\title{
Insulin effect on bupivacaine-induced cardiotoxicity in rabbits
}

\author{
Yun Suk Choi ${ }^{1}$, and Kook Hyun Lee ${ }^{2}$ \\ Deparment of Anesthesiology and Pain Medicine, ${ }^{1}$ Jeju National University Hospital, Jeju, ${ }^{2}$ Seoul National University Hospital, Seoul, Korea
}

Background: Resuscitation following bupivacaine-induced cardiovascular collapse is difficult and often refractory to conventional treatment. This study was performed to assess the effect of insulin on bupivacaine-induced cardiovascular collapse in pentobarbital-anesthetized rabbits.

Methods: Bupivacaine was administered at $0.75 \mathrm{mg} / \mathrm{kg} / \mathrm{min}$ until the heart rate decreased to $65 \mathrm{beats} / \mathrm{min}$. A bolus of regular insulin $(2 \mathrm{U} / \mathrm{kg}$ ) was administered intravenously at the bupivacaine infusion endpoint (BIE) in the insulin group ( $\mathrm{n}=8)$, and $2 \mathrm{~mL}$ of $0.9 \% \mathrm{NaCl}$ was administered to the control group $(\mathrm{n}=8)$.

Results: All animals in the insulin group survived and four animals died in the control group. Arrythymia was rare 10 minutes after the BIE in the insulin group.

Conclusions: Bupivacaine-induced cardiovascular collapse can be effectively reversed with an insulin injection, probably through facilitation of cardiac conduction and contraction. (Korean J Anesthesiol 2011; 61: 493-498)

Key Words: Bupivacaine, Cardiac arrhythmia, Insulin.

\section{Introduction}

Since cardiotoxicity induced by bupivacaine was first reported by Albright [1] and has been widely used in the areas of pain control and obstetrics, it is known to be refractory to cardiopulmonary resuscitation with epinephrine. Thereafter, numerous studies were performed to investigate the mechanism and treatment modalities of bupivacaine-induced cardiotoxicity [2-7]. This cardiotoxicity is caused by inhibiting heart muscle conduction and contractility. Bupivacaine inhibits cardiac conduction by decreasing upstroke velocity of action potentials through blockage of myocardial voltage-sensitive sodium channels [2], by delaying repolarization through the inhibition of transient outward $\mathrm{K}^{+}$current (Ito), and by prolonging action potential duration [3]. In addition, bupivacaine inhibits myocardial contractility by suppressing $\mathrm{Ca}^{2+}$ excretion from the sarcoplasmic reticulum [4].

Insulin activates Ito and $\mathrm{Ca}^{2+}$ transport into the sarcoplasmic reticulum and increases cytoplasmic glucose concentration and mitochondrial pyruvate availability $[8,9]$. Experimental studies in dogs have demonstrated that administering insulin successfully treats severe bupivacaine-induced cardiotoxicity and that heart rate, $\mathrm{QT}_{\mathrm{c}}$, PR interval, QRS duration, and cardiac output improve more rapidly in an insulin-treated group than

Received: March 12, 2010. Revised: 1st, March 26, 2010; 2nd, June 24, 2010. Accepted: May 11, 2011.

Corresponding author: Kook Hyun Lee, M.D., Deparment of Anesthesiology and Pain Medicine, Seoul National University Hospital, 101, Daehak-ro, Jongno-gu, Seoul 110-744, Korea. Tel: 82-2-2072-2567, Fax: 82-2-747-5639, E-mail: leekh@snu.ac.kr

This is a thesis for a doctor's degree.

@ This is an open-access article distributed under the terms of the Creative Commons Attribution Non-Commercial License (http:// creativecommons.org/licenses/by-nc/3.0/), which permits unrestricted non-commercial use, distribution, and reproduction in any medium, provided the original work is properly cited. 
those in a control group [10-12].

Cardiac contraction and ventricular conduction is inhibited severely during a fast heart rate, when bupivacaine concentration increases and QRS duration is prolonged [2,5]. We presumed that a rabbit is a more suitable animal than a dog for severe bupivacaine-induced cardiac toxicity because of its faster heart rate. Therefore, we evaluated the effect of insulin on bupivacaine-induced cardiac toxicity and cardiac conduction blockage in terms of hematological and electrocardiogram (ECG) parameters in rabbits.

\section{Materials and Methods}

This experimental study protocol was approved by the Animal Care and Use Committee of Seoul National University College of Medicine.

Sixteen New Zealand white rabbits, weighing $2.5 \mathrm{~kg}$, were used. After an intramuscular injection of ketamine $(15 \mathrm{mg} / \mathrm{kg})$ and xylazine $(10 \mathrm{mg} / \mathrm{kg})$, a venous route was established in the ear marginal vein, and endotracheal intubation was performed. Vecuronium $(0.1 \mathrm{mg} / \mathrm{kg})$ was intravenously injected, and a Servo 900 C device (Siemens, Solna, Sweden) was connected to the tracheal tube. Respiratory rate and tidal volume were controlled at a $\mathrm{Pa}_{\mathrm{CO} 2}$ of $40 \mathrm{mmHg}$. Anesthesia was maintained by continuous intravenous administration of pentobarbital (3-5 $\mathrm{mg} / \mathrm{kg} / \mathrm{h})$ and injections of vecuronium $(0.01 \mathrm{mg} / \mathrm{kg})$ every 30 minutes.

The right carotid artery was incised, and a $20 \mathrm{G}$ arterial catheter was inserted to continuously measure blood pressure and to collect blood samples. A central venous catheter was inserted into the right jugular vein to measure central venous pressure and to administer fluids. Limb ECG leads were attached to monitor heart rate and arrhythmias in lead II. A 12-lead resting ECG analysis system (MAC 8 Marquette, Los Angeles, CA, USA) was used.

Baseline hematological data and a blood gas analysis were collected after a 10-minute stabilization period, and then pentobarbital /bupivacaine was intravenously administered.

In a preliminary experiment, the infusion velocity of bupivacaine was $0.5-1.0 \mathrm{mg} / \mathrm{kg} / \mathrm{min}$, and the optimum infusion velocity was $0.75 \mathrm{mg} / \mathrm{kg} / \mathrm{min}$, based on the finding that hematological changes were more predictable (data are not shown).

We found that the rabbits had difficulty awaking spontaneously from the anesthesia with an approximate heart rate of $65 / \mathrm{min}$. At that time, mean blood pressure was almost 20 $\mathrm{mmHg}$, which was determined to be the cardiac depression point (bupivacaine infusion endpoint, BIE) and the death rate was $50 \%$. The intravenous infusion of bupivacaine and pentobarbital was stopped at the BIE, and the rabbits were divided into two groups; those that were administered regular insulin (2 $\mathrm{U} / \mathrm{kg}$ ) mixed with $2 \mathrm{ml}$ of $9 \% \mathrm{NaCl}$ solution (insulin group) and those that were administered the same volume of $0.9 \% \mathrm{NaCl}$ solution (control group). Hematological data, such as mean arterial blood pressure and heart rate and ECG, were obtained every 5 minutes between the starting point and the BIE. An arterial blood gas analysis and electrolytes $\left(\mathrm{Na}^{+}, \mathrm{K}^{+}\right.$, $\mathrm{Ca}^{2+}$ ), blood glucose, and blood drug concentrations were conducted every 10 minutes. These data were obtained again at the BIE. The same collection procedures were performed for 30 minutes after the BIE. The arterial blood samples collected to measure blood drug concentration were centrifuged at 2,500 rpm for 20 minutes, and the plasma was separated and stored at $-70^{\circ} \mathrm{C}$. The blood bupivacaine concentration was measured by high performance liquid chromatography. Sodium bicarbonate ( $2 \mathrm{mEq} / \mathrm{kg} / \mathrm{h}$ ) was continuously administered intravenously to prevent acidosis during the experiment, and $2 \mathrm{ml}$ of $50 \% \mathrm{D} /$ $\mathrm{W}$ was administered if blood glucose was $\leq 60 \mathrm{mg} / \mathrm{dl}$. Survival was defined when sinus rhythm occurred and heart rate/mean blood pressure recovered to baseline values after BIE for 30 $\mathrm{min}$. All rabbits were sacrificed by infusing $40 \mathrm{mEq} \mathrm{KCl}$ after completing the experiment.

Data are expressed as mean \pm SD. Survival rate and frequency of cardiac arrythmia between the two groups was compared using Fisher's exact test. Differences in body weight and blood hemoglobin concentration measured at the start of the experiment and the total volume of infused bupivacaine and bupivacaine concentration at the BIE were analyzed using the unpaired t-test. A repeated-measures analysis of variance was used to compare hematological data and bupivacaine concentrations at different time points within the same group. Post hoc analyses were performed using the Bonferroni-adjusted test. A P value $<0.05$ was considered statistically significant. All statistical analyses were performed using SPSS version 12.0 (SPSS Inc, Chicago, IL, USA).

\section{Results}

No significant differences were observed for body weight or hemoglobin concentration between the two groups at the start of the experiment. No significant differences in the time interval between the start point and the BIE, the volume of infused bupivacaine, or bupivacaine concentration at the BIE were observed between the two groups. No significant differences in arrhythmia, heart rate, mean blood pressure, PR interval, or QRS duration were observed between the two groups from the start of the experiment to the BIE (Tables 1, 2, and 3).

The BIE heart rate and mean arterial blood pressure decreased significantly as bupivacaine was infused, and the PR interval and QRS duration increased significantly compared to baseline 
Table 1. Baseline Data of the Experimental Rabbits

\begin{tabular}{lccc}
\hline \multicolumn{1}{c}{ Parameter } & $\begin{array}{c}\text { Control group } \\
(\mathrm{n}=8)\end{array}$ & $\begin{array}{c}\text { Insulin group } \\
(\mathrm{n}=8)\end{array}$ & P values \\
\hline Weight on baseline $(\mathrm{kg})$ & $2.7 \pm 0.4$ & $2.7 \pm 0.3$ & $\mathrm{Ns}$ \\
Hb on baseline $(\mathrm{g} / \mathrm{dl})$ & $10.3 \pm 0.8$ & $10.5 \pm 1.0$ & $\mathrm{Ns}$ \\
$\begin{array}{l}\text { Amount of bupivacaine } \\
\text { infused (mg) to BIE }\end{array}$ & $12 \pm 8.2$ & $15 \pm 14.6$ & $\mathrm{Ns}$ \\
$\begin{array}{l}\text { Plasma bupivacaine } \\
\text { concentration on BIE }\end{array}$ & $16.5 \pm 4.4$ & $21.6 \pm 15.3$ & $\mathrm{Ns}$ \\
$\begin{array}{l}\text { (mcg/ml) } \\
\text { Time to BIE (sec) }\end{array}$ & $1,003 \pm 741.7$ & $1,219 \pm 1,174.2$ & $\mathrm{Ns}$ \\
Number of survival & 4 & 8 & $0.038^{*}$ \\
\hline
\end{tabular}

Values are mean \pm SD. Ns: non-significant, BIE: bupivacaine infusion endpoint. $* \mathrm{P}<0.05$.

Table 2. Number of Animals with Arrhythmias

\begin{tabular}{llccc}
\hline \multicolumn{1}{c}{ Arrhythmia } & $\begin{array}{c}\text { Control } \\
\text { group } \\
(\mathrm{n}=8)\end{array}$ & $\begin{array}{c}\text { Insulin } \\
\text { group } \\
(\mathrm{n}=8)\end{array}$ & P values \\
\hline Before BIE & $\begin{array}{l}\text { Sinus bradycardia c } \\
\text { QRS widening }\end{array}$ & 4 & 5 & Ns \\
& Bigemy & 2 & 1 & Ns \\
& PVC & 1 & 1 & Ns \\
& AIVR & 0 & 1 & Ns \\
& Junctional rhythm & 0 & 1 & Ns \\
& $\begin{array}{l}\text { Polymorphic ventricular } \\
\text { tachycardia }\end{array}$ & 1 & 0 & Ns \\
& Polymorphic ventricular & 5 & 6 & Ns \\
& tachycardia & & & \\
& PVC & 4 & 3 & Ns \\
& AV Block & 2 & 2 & Ns \\
& AIVR & 1 & 0 & Ns \\
& Asystole, EMD & 4 & 0 & $0.038^{*}$
\end{tabular}

PVC: premature ventricular contractions, AIVR: accelerated idioventricular rhythm, EMD: electromechanical dissociation, BIE: bupivacaine infusion endpoint, Ns: non-significant. ${ }^{*} \mathrm{P}<0.05$ is significant. values $(\mathrm{P}<0.05)$. All rabbits showed a normal sinus rhythm at the start, but the PR interval and QRS duration increased as bupivacaine was infused. QRS duration increased earlier than the PR interval, and the changes in S wave amplitude appeared earliest in the QRS complex (Fig. 1). PR interval increased only at the BIE in the control group, whereas it increased for up to 20 minutes after the BIE in the insulin group, compared to baseline values. QRS duration increased for up to 5 minutes after the BIE in the control group, whereas it increased for up to 25 minutes after the BIE in the insulin group (Table 3 ). Heart rate decreased significantly for up to 15 minutes after the BIE in the insulin group compared to baseline values $(\mathrm{P}<0.05)$ (Table 3$)$.

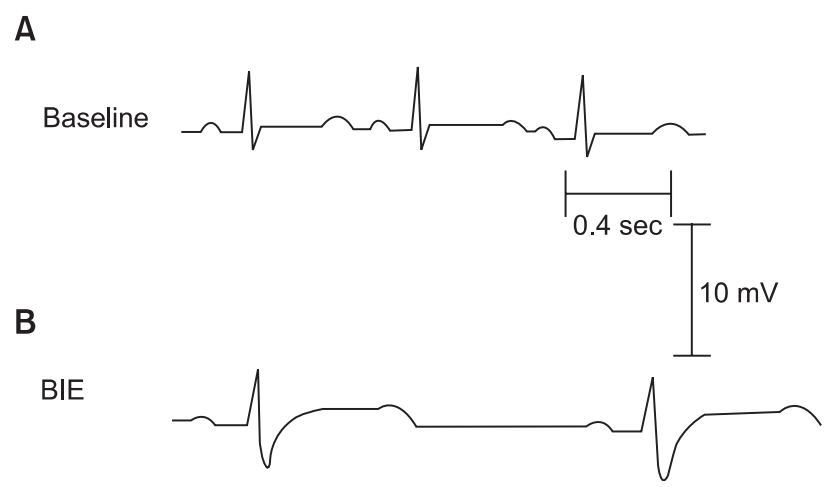

Fig. 1. Electrocardiographic changes induced by bupivacaine infusion in rabbits. Lead II electrocardiogram recorded at $25 \mathrm{~mm} / \mathrm{s}$. (A) During the baseline period, the values were: heart rate, $190 \mathrm{bpm} / \mathrm{min}$; PR interval, $80 \mathrm{~ms}$; QRS duration, $40 \mathrm{~ms}$; QTC interval, $269 \mathrm{msec}$. (B) Bupivacaine at a concentration of $20.2 \mu \mathrm{g} / \mathrm{ml}$ administered at the bupivacaine infusion endpoint (BIE) resulted in the following alterations: heart rate, $67 \mathrm{bpm} / \mathrm{min}$; PR interval, $140 \mathrm{~ms}$; QRS duration, $62 \mathrm{~ms}$; QTC interval, $344 \mathrm{msec}$.

Table 3. Comparison of Hemodynamic Data between the Control and Insulin Groups

\begin{tabular}{|c|c|c|c|c|c|c|c|c|c|}
\hline & Group & Base & $\mathrm{BIE}$ & $5 \mathrm{~min}$ & $10 \mathrm{~min}$ & $15 \mathrm{~min}$ & $20 \mathrm{~min}$ & $25 \min$ & $30 \mathrm{~min}$ \\
\hline \multirow[t]{2}{*}{$\mathrm{HR}$} & Control & $\begin{array}{c}144.5 \pm 25.4 \\
(\mathrm{~N}=8)\end{array}$ & $\begin{array}{l}65.7 \pm 5.28 * \\
\quad(\mathrm{~N}=8)\end{array}$ & $\begin{array}{c}81.0 \pm 14.6^{*} \\
(\mathrm{~N}=6)\end{array}$ & $\begin{array}{c}105.7 \pm 32.5^{*} \\
(\mathrm{~N}=5)\end{array}$ & $\begin{array}{c}128.0 \pm 37.0 * \\
(\mathrm{~N}=4)\end{array}$ & $\begin{array}{c}149.2 \pm 40.8 \\
(\mathrm{~N}=4)\end{array}$ & $\begin{array}{c}186.0 \pm 18.4 \\
(\mathrm{~N}=4)\end{array}$ & $\begin{array}{c}197.0 \pm 24.1 \\
(\mathrm{~N}=4)\end{array}$ \\
\hline & Insulin & $\begin{array}{c}157.0 \pm 18.4 \\
(\mathrm{~N}=8)\end{array}$ & $66.0 \pm 2.9 *$ & $101.6 \pm 21.8 *$ & $142.3 \pm 43.1$ & $162.7 \pm 48.3$ & $179.5 \pm 39.2$ & $178.5 \pm 36.2$ & $178.7 \pm 29.4$ \\
\hline \multirow[t]{2}{*}{ MAP (mmHg) } & Control & $\begin{array}{c}67.5 \pm 16.3 \\
(\mathrm{~N}=8)\end{array}$ & $\begin{array}{c}18.8 \pm 4.9 * \\
(\mathrm{~N}=8)\end{array}$ & $\begin{array}{c}21.5 \pm 4.3^{*} \\
(\mathrm{~N}=6)\end{array}$ & $\begin{array}{c}29.2 \pm 2.7^{*} \\
(\mathrm{~N}=5)\end{array}$ & $\begin{array}{c}39.2 \pm 5.0 \\
(\mathrm{~N}=4)\end{array}$ & $\begin{array}{c}44.5 \pm 5.2 \\
(\mathrm{~N}=4)\end{array}$ & $\begin{array}{c}49.2 \pm 22.8 \\
(\mathrm{~N}=4)\end{array}$ & $\begin{array}{c}47.5 \pm 18.1 \\
(\mathrm{~N}=4)\end{array}$ \\
\hline & Insulin & $\begin{array}{c}60.7 \pm 12.3 \\
(\mathrm{~N}=8)\end{array}$ & $22.0 \pm 6.7^{*}$ & $32.3 \pm 14.5^{*}$ & $36.5 \pm 14.4$ & $44.5 \pm 19.0$ & $47.8 \pm 12.7$ & $51.7 \pm 10.4$ & $48.8 \pm 13.0$ \\
\hline \multirow[t]{2}{*}{ PR interval } & Control & $\begin{array}{c}86.6 \pm 12.9 \\
(\mathrm{~N}=8)\end{array}$ & $\begin{array}{c}104.8 \pm 19.8^{*} \\
(\mathrm{~N}=5)\end{array}$ & $\begin{array}{c}120.7 \pm 16.9 \\
(\mathrm{~N}=4)\end{array}$ & $\begin{array}{c}109.7 \pm 23.3 \\
(\mathrm{~N}=4)\end{array}$ & $\begin{array}{c}113.2 \pm 22.5 \\
(\mathrm{~N}=4)\end{array}$ & $\begin{array}{c}107.5 \pm 18.4 \\
(\mathrm{~N}=3)\end{array}$ & $\begin{array}{c}105 \pm 17.3 \\
(\mathrm{~N}=3)\end{array}$ & $\begin{array}{c}105 \pm 10.8 \\
(\mathrm{~N}=2)\end{array}$ \\
\hline & Insulin & $\begin{array}{c}81.7 \pm 9.0 \\
(\mathrm{~N}=8)\end{array}$ & $\begin{array}{c}112.2 \pm 17.2 * \\
(\mathrm{~N}=8)\end{array}$ & $\begin{array}{c}119.7 \pm 18.8 * \\
(\mathrm{~N}=8)\end{array}$ & $\begin{array}{c}126.7 \pm 15.5^{*} \\
(\mathrm{~N}=6)\end{array}$ & $\begin{array}{c}120.2 \pm 15.5^{*} \\
(\mathrm{~N}=6)\end{array}$ & $\begin{array}{c}113 \pm 18.1^{*} \\
(\mathrm{~N}=6)\end{array}$ & $\begin{array}{c}106.6 \pm 20.6 \\
(\mathrm{~N}=6)\end{array}$ & $\begin{array}{c}102.5 \pm 20.4 \\
(\mathrm{~N}=6)\end{array}$ \\
\hline \multirow[t]{2}{*}{ QRS duration } & Control & $\begin{array}{c}34.6 \pm 5.8 \\
(\mathrm{~N}=8)\end{array}$ & $\begin{array}{c}63.8 \pm 18.1^{*} \\
\quad(\mathrm{~N}=6)\end{array}$ & $\begin{array}{c}62.5 \pm 13.2^{*} \\
(\mathrm{~N}=4)\end{array}$ & $\begin{array}{c}73.2 \pm 25.8 \\
(\mathrm{~N}=4)\end{array}$ & $\begin{array}{c}53.0 \pm 10.2 \\
(\mathrm{~N}=4)\end{array}$ & $\begin{array}{l}50 \pm 10.4 \\
(\mathrm{~N}=4)\end{array}$ & $\begin{array}{c}42.5 \pm 7.6 \\
(\mathrm{~N}=4)\end{array}$ & $\begin{array}{c}41.2 \pm 6.2 \\
(\mathrm{~N}=4)\end{array}$ \\
\hline & Insulin & $\begin{array}{c}39.1 \pm 6.4 \\
(\mathrm{~N}=8)\end{array}$ & $\begin{array}{c}71.6 \pm 10.0 * \\
(\mathrm{~N}=8)\end{array}$ & $\begin{array}{c}73.1 \pm 9.4^{*} \\
(\mathrm{~N}=8)\end{array}$ & $\begin{array}{c}63.4 \pm 13.8^{*} \\
(\mathrm{~N}=6)\end{array}$ & $\begin{array}{c}58.5 \pm 15.1^{*} \\
\quad(\mathrm{~N}=7)\end{array}$ & $\begin{array}{c}53.3 \pm 14.3^{*} \\
(\mathrm{~N}=7)\end{array}$ & $\begin{array}{c}54.1 \pm 14.3^{*} \\
\quad(\mathrm{~N}=8)\end{array}$ & $\begin{array}{c}43.5 \pm 10.0 \\
(\mathrm{~N}=7)\end{array}$ \\
\hline \multirow[t]{2}{*}{$\begin{array}{l}\text { Plasma bupivac } \\
\text { conc. }(\mathrm{mcg} / \mathrm{ml})\end{array}$} & Control & 0 & $\begin{array}{c}16.5 \pm 3.4^{*} \\
(\mathrm{~N}=8)\end{array}$ & & $\begin{array}{l}3.8 \pm 2.8^{*} \\
(\mathrm{~N}=4)\end{array}$ & & $\begin{array}{l}2.0 \pm 1.2^{*} \\
(\mathrm{~N}=4)\end{array}$ & & $\begin{array}{l}1.3 \pm 0.7^{*} \\
(\mathrm{~N}=4)\end{array}$ \\
\hline & Insulin & 0 & $21.6 \pm 5.7^{*}$ & & $2.8 \pm 1.3^{*}$ & & $1.7 \pm 1.1^{*}$ & & $1.2 \pm 1.0^{*}$ \\
\hline
\end{tabular}

Values are mean \pm SD. MAP: mean arterial pressure, HR: heart rate, BIE: bupivacaine infusion endpoint. *P $<0.05$ vs. baseline. 
Table 2 shows the cardiac arrhythmias that occurred before and after the BIE. The most common cardiac arrhythmia was sinus bradycardia associated with QRS widening ( $\mathrm{n}=4$ in the control group and $n=5$ in the insulin group) (Fig. 1). All rabbits in the control group, which showed electromechanical dissociation $(\mathrm{n}=2)$ and asystole $(\mathrm{n}=2)$, died at $1,4,8$, and 17 minutes after the BIE. Severe cardiac arrhythmias, such as electromechanical dissociation and asystole, occurred less frequently in the insulin group $(\mathrm{P}<0.05)$. Four of eight rabbits in the control group survived, whereas all eight rabbits in the insulin group survived $(\mathrm{P}<0.05)$.

Blood bupivacaine concentration decreased abruptly 10 minutes after the BIE, and no significant differences in the concentration were observed at different time points between the two groups (Table 3). The arterial blood gas analysis revealed no significant differences in $\mathrm{pH}, \mathrm{P}_{\mathrm{a}} \mathrm{CO}_{2}$, or $\mathrm{P}_{\mathrm{a}} \mathrm{O}_{2}$ between the two groups at different time points, and the values were within the normal range in both groups. Blood $\mathrm{Na}^{+}$concentration was not significantly different either. Blood $\mathrm{Ca}^{2+}$ concentration decreased at the BIE compared to baseline values in the control group and decreased for up to 10 minutes after the BIE in the insulin group, but the differences were not statistically significant. Blood $\mathrm{K}^{+}$concentration, measured 10 minutes after the BIE, decreased more significantly in the insulin group than that in the control group (Table 4). Although blood glucose concentration in the insulin group increased 10 minutes after the BIE compared to that in the control group, blood glucose concentration was not significantly different between the two groups. Hyperglycemia $\geq 300 \mathrm{mg} / \mathrm{dl}$ occurred in two rabbits in the control group. Hypoglycemia $\leq 60 \mathrm{mg} / \mathrm{dl}$ occurred in one rabbit in the insulin group, which received $2 \mathrm{ml}$ of $5 \% \mathrm{D} / \mathrm{W}$ solution.

\section{Discussion}

We evaluated the effect of insulin on bupivacaine-induced cardiotoxicity in rabbits. Four of the eight rabbits in the control group survived after the BIE, whereas all eight rabbits in the insulin group survived. Severe arrhythmias, such as electromechanical dissociation and asystole, occurred after the BIE in two rabbits each in the control group, whereas these arrhythmias occurred less frequently in the insulin group. However, the heart rate and mean blood pressure recovery patterns were not significantly different between the groups. Previous studies on dogs have demonstrated that insulin rapidly improves heart rate, $\mathrm{QT}_{c}$, $\mathrm{PR}$ interval, and QRS duration and significantly increases contractility during bupivacaine-induced cardiotoxicity [10-12]. In our study, the improvement in heart rate, PR interval, and QRS duration was not significantly different between the insulin and control groups, but the frequency of severe arrhythmias was significantly lower in the insulin group. Based on these results, insulin may decrease the frequency of severe arrhythmias and subsequently increase survival rate. Further studies are needed to confirm this result.

Humans, dogs, and rabbits have similar cardiac contraction mechanisms [13]. Considering that rabbits have a more rapid heart rate than dogs, rabbits were used to evaluate the effect of insulin on heart rate. Our pilot study of rabbits determined that spontaneous wakening from anesthesia was difficult at an approximate heart rate of $65 / \mathrm{min}$, so the BIE was determined to be $65 / \mathrm{min}$. At this BIE, mean blood pressure was $20.2 \pm 9.6$ $\mathrm{mmHg}$ in the control group and $22.6 \pm 8.9 \mathrm{mmHg}$ in the insulin group, but the difference was not statistically significant (Table 1). Bupivacaine-induced cardiotoxicity is a conduction disorder caused by inhibiting sodium channels within the ventricle,

Table 4. Change in Arterial Blood Gases, Serum Electrolytes, and Plasma-Glucose Concentrations between the Control and Insulin Groups

\begin{tabular}{|c|c|c|c|c|c|c|}
\hline & Group & Base & BIE & $10 \mathrm{~min}$ & $20 \mathrm{~min}$ & $30 \mathrm{~min}$ \\
\hline \multirow[t]{2}{*}{$\mathrm{PH}$} & Control & $7.4 \pm 0.07$ & $7.5 \pm 0.18^{\dagger}$ & $7.47 \pm 0.20^{\dagger}$ & $7.41 \pm 0.09$ & $7.44 \pm 0.05$ \\
\hline & Insulin & $7.41 \pm 0.07$ & $7.41 \pm 0.18$ & $7.36 \pm 0.10$ & $7.36 \pm 0.09$ & $7.37 \pm 0.10$ \\
\hline \multirow{2}{*}{$\mathrm{PaO}_{2}(\mathrm{mmHg})$} & Control & $491.0 \pm 49.0$ & $479.4 \pm 82.6$ & $479.4 \pm 82.6$ & $527.2 \pm 18.1$ & $538.6 \pm 5.6$ \\
\hline & Insulin & $494.3 \pm 67.9$ & $446.0 \pm 107.8$ & $507.3 \pm 78.4$ & $503.3 \pm 73.0$ & $448.1 \pm 129.2$ \\
\hline \multirow[t]{2}{*}{$\mathrm{PaCO}_{2}(\mathrm{mmHg})$} & Control & $41.0 \pm 10.5$ & $32.0 \pm 17.8$ & $32.4 \pm 12.9$ & $39.3 \pm 4.5$ & $35.3 \pm 4.5$ \\
\hline & Insulin & $34.1 \pm 5.4$ & $35.8 \pm 12.6$ & $39.1 \pm 10.7^{\dagger}$ & $40.1 \pm 10.3^{\dagger}$ & $40.5 \pm 9.9^{\dagger}$ \\
\hline \multirow[t]{2}{*}{$\mathrm{Na}^{+}(\mathrm{mEq} / \mathrm{L})$} & Control & $143.1 \pm 1.8$ & $152.6 \pm 11.7$ & $148.9 \pm 3.6$ & $148.8 \pm 3.6$ & $149.1 \pm 4.0$ \\
\hline & Insulin & $146.2 \pm 9.6$ & $146 \pm 4.6$ & $146.3 \pm 4.5$ & $147.4 \pm 4.0$ & $147.9 \pm 3.3$ \\
\hline \multirow[t]{2}{*}{$\mathrm{K}^{+}(\mathrm{mEq} / \mathrm{L})$} & Control & $3.21 \pm 0.4$ & $3.28 \pm 0.17$ & $3.30 \pm 0.66$ & $3.00 \pm 0.14$ & $3.10 \pm 0.10$ \\
\hline & Insulin & $3.10 \pm 0.76$ & $2.97 \pm 0.50$ & $2.54 \pm 0.44^{*}$ & $2.62 \pm 0.69$ & $2.77 \pm 0.76$ \\
\hline \multirow[t]{2}{*}{$\mathrm{Ca}^{2+}(\mathrm{mEq} / \mathrm{L})$} & Control & $2.70 \pm 0.29$ & $2.15 \pm 0.49^{\dagger}$ & $2.24 \pm 0.35$ & $2.20 \pm 0.35$ & $2.34 \pm 0.93$ \\
\hline & Insulin & $2.66 \pm 0.46$ & $2.24 \pm 0.45^{\dagger}$ & $2.09 \pm 0.44^{\dagger}$ & $2.11 \pm 0.38$ & $2.11 \pm 0.39$ \\
\hline \multirow[t]{2}{*}{ Glucose (mg/dl) } & Control & $184 \pm 84$ & $206 \pm 137$ & $190.7 \pm 139$ & $176 \pm 144$ & $154 \pm 144$ \\
\hline & Insulin & $164 \pm 57$ & $193 \pm 69$ & $205 \pm 45^{\dagger}$ & $151 \pm 38$ & $132 \pm 54$ \\
\hline
\end{tabular}

Values are mean \pm SD. BIE: bupivacaine infusion endpoint. Control group: base $B I E(n=8), 10 \min (n=5), 20 \min (n=4), 30 \min (n=4) . * P<0.05$ vs. control group. ${ }^{\dagger} \mathrm{P}<0.05$ vs. baseline. 
which is revealed as a prolongation of PR interval and QRS widening $[14,15]$. In our study, PR interval and QRS widening increased at the BIE compared to those at baseline. During QRS widening, the S-wave amplitude in lead III increased first, which was similar to the result of a previous study in dogs by Jeong et al. [16]. They reported that changes in S-wave amplitude reflect a decrease in cardiac output and can be used as an indicator of bupivacaine-induced cardiotoxicity. However, further studies are needed to determine whether cardiac output is related to S-wave amplitude. PR interval and QRS widening were not normalized in either group and increased for up to 30 minutes after the BIE but recovered to sinus rhythm. Persistent prolongation of the PR interval may have been related to the decrease in blood $\mathrm{K}^{+}$concentration in the insulin group. However, the difference in blood $\mathrm{K}^{+}$concentration between the two groups was not statistically significant because of early death of animals in the control group and because the PR interval was not checked in both groups. Because bupivacaine binds to sodium, potassium, and calcium channels within the myocardium in a fast-in, slow-out manner [2], a conduction disorder may persist for a longer time, even if bupivacaine concentration decreases. Additionally, mean blood pressure decreases due to a bupivacaine-induced myocardial contractility disorder, subsequently decreasing coronary perfusion pressure and producing numerous ischemic areas in the myocardium. A previous study in rabbits demonstrated that bupivacaine induces atrioventricular block and re-entrant ventricular dysrhythmias by inhibiting conduction at atrial, ventricular, and atrioventricular levels [17]. In our study, conduction block and re-entrant ventricular dysrhythmias occurred as in previous studies.

Insulin activates Ito and $\mathrm{Ca}^{2+}$ transport into the sarcoplasmic reticulum and increases cytoplasmic glucose concentration and mitochondrial pyruvate availability $[8,9]$. Furthermore, insulin facilitates potassium transport from the extracellular to the intracellular space through an $\mathrm{Na}^{+}-\mathrm{K}^{+}$pump in skeletal muscles and the liver, subsequently decreasing blood $\mathrm{K}^{+}$concentration. This effect of insulin is proportional to its infused volume, occurs within 10 minutes of administration, and lasts more than 60 minutes [18]. This may explain our result that blood $\mathrm{K}^{+}$ concentration was lower in the insulin group than that in the control group 10 minutes after insulin administration. Although the half-life of insulin is 5 minutes when injected intravenously, its pharmacologic effect lasts longer than the half life because it binds strongly to receptors [11]. In our study, only blood glucose concentration at the 10 min BIE increased in the insulin group compared to baseline values, but no other significant differences were observed between the two groups. This phenomenon is related to the blood glucose increase during acute cardiopulmonary resuscitation [19].
Bupivacaine-induced cardiotoxicity increases in the presence of acidosis or hypoxia [20]. In our study, the amount of sodium bicarbonate was controlled during intravenous infusion based on the arterial blood gas analysis results. As a result, metabolic acidosis did not occur in any rabbit, and no significant difference in arterial $\mathrm{pH}$ was observed between the two groups at different time points. We also prevented hypoxia by mechanically ventilating with $100 \%$ oxygen. We attempted to evaluate the effect of bupivacaine on conduction but found no significant difference in the recovery of heart rate and mean blood pressure. Because the duration of insulin action is $>1$ hour, additional studies for $\geq 1$ hour are needed to confirm our results.

In conclusion, our results suggest that insulin may decrease the frequency of cardiac arrhythmias and, thus, increase survival in rabbits with bupivacaine-induced cardiotoxicity.

\section{Acknowledgements}

The 26th Annual Conference of the Korean Society of Critical Care Medicine, 2006, Seoul, Korea.

\section{References}

1. Albright GA. Cardiac arrest following regional anesthesia with etidocaine or bupivacaine. Anesthesiology 1979; 51: 285-7.

2. Clarkson CW, Hondeghem LM. Mechanism for bupivacaine depression of cardiac conduction: fast block of sodium channels during the action potential with slow recovery from block during diastole. Anesthesiology 1985; 62: 396-405.

3. Castle NA. Bupivacaine inhibits the transient outward K+ current but not the inward rectifier in rat ventricular myocytes. J Pharmacol Exp Ther 1990; 255: 1038-46.

4. Lynch C 3rd. Depression of myocardial contractility in vitro by bupivacaine, etidocaine, and lidocaine. Anesth Analg 1986; 65: 551-9.

5. Lacombe P, Blaise G, Hollmann C, Tanguay M, Loulmet D. Isoproterenol corrects the effects of bupivacaine on the electrophysiologic properties of the isolated rabbit heart. Anesth Analg 1991; 72: 70-4.

6. Adsan H, Tulunay M, Onaran $\mathrm{O}$. The effects of verapamil and nimodipine on bupivacaine-induced cardiotoxicity in rats: An in vivo and in vitro study. Anesth Analg 1998; 86: 818-24.

7. Boban M, Stowe DF, Gross GJ, Pieper GM, Kampine JP, Bosnjak ZJ. Potassium channel openers attenuate atrioventricular block by bupivacaine in isolated hearts. Anesth Analg 1993; 76: 1259-65.

8. Zierler K, Wu FS. An early outward transient K+ current that depends on a preceding $\mathrm{Na}+$ current and is enhanced by insulin. Pflugers Arch 1992; 422: 267-72.

9. Gupta MP, Innes IR, Dhalla NS. Characterization of insulin receptors in cardiac sarcolemmal and sarcoplasmic reticular membranes. J Cardiovasc Pharmacol 1987; 10: 259-67.

10. Kim JT, Jung CW, Lee KH. The effect of insulin on the resuscitation of bupivacaine-induced severe cardiovascular toxicity in dogs. Anesth Analg 2004; 99: 728-33.

11. Cho HS, Lee JJ, Chung IS, Shin BS, Kim JA, Lee KH. Insulin reverses 
bupivacaine-induced cardiac depression in dogs. Anesth Analg 2000; 91: 1096-102.

12. Cho HS, Lee KH, Lee S, Lee JJ, Shin BS. The Effects of Insulin in Treating Bupivacaine-Induced Cardiac Depression. Korean J Anesthesiol 2000; 38: 130-8.

13. Su Z, Li F, Spitzer KW, Yao A, Ritter M, Barry WH. Comparison of sarcoplasmic reticulum Ca2+-ATPase function in human, dog, rabbit, and mouse ventricular myocytes. J Mol Cell Cardiol 2003; 35 : 761-7.

14. Lacombe P, Blaise G, Loulmet D, Hollmann C. Electrophysiologic effects of bupivacaine in the isolated rabbit heart. Anesth Analg 1991; 72: 62-9.

15. Simon L, Kariya N, Edouard A, Benhamou D, Mazoit JX. Effect of bupivacaine on the isolated rabbit heart: developmental aspect on ventricular conduction and contractility. Anesthesiology 2004; 101: 937-44.
16. Jeong JY, Kim JT, Lee KH. The Changes of S-wave Amplitude in Lead III for Detecting the Early Bupivacaine-induced Cardiotoxicity. Korean J Anesthesiol 2004; 46: 599-603.

17. Simon L, Kariya N, Edouard A, Benhamou D, Mazoit JX. Effect of Bupivacaine on the Isolated Rabbit Heart: developmental Aspect on Ventricular Conduction and Contractility. Anesthesiology 2004; 101: 937-44.

18. Blumberg A, Weidmann P, Shaw S, Gnädinger M. Effect of various therapeutic approaches on plasma potassium and major regulating factors in terminal renal failure. Am J Med 1988; 85: 507-12.

19. Beiser DG, Carr GE, Edelson DP, Peberdy MA, Hoek TL. Derangements in blood glucose following initial resuscitation from inhospital cardiac arrest: a report from the national registry of cardiopulmonary resuscitation. Resuscitation 2009; 80: 624-30.

20. Tucker GT. Pharmacokineics of local anaesthetics. Br J Anaesth 1986; 58: 717-3. 